\title{
ELECTRON MICROPROBE DATA PROCESSING: A COMPARISON OF THREE COMPUTATIONAL METHODS
}

\author{
JaAk Ko Sirvola
}

\begin{abstract}
Sirvola, JAAK KO 1973: Electron microprobe data processing: a comparison of three computational methods. Bull. Geol. Soc. Finland 45, 43-48.

A fourfold series of microprobe analyses was performed. The materials examined consisted of five specimens of garnet and one of silicate glass, all currently used as microprobe standards. During the microprobe data reduction, three, basically different types of computer programs were applied. The results are practically independent of the computer program used. The excellence of the reproducibility within the four series of analyses is evident. The microprobe data are also compared with conventional wet chemical analyses.
\end{abstract}

Jaakko Siivola, Geological Survey of Finland, 02150 Otaniemi, Finland.

\section{Introduction}

It is generally known that the calculations required in the treatment of microprobe data are quite tedious and time-consuming. This is especially true when it is done by hand or a simple desk-top calculator is used. To avoid this problem, many different types of computer programs have been developed. It has been estimated that at least 150 programs should be available by 1975. An exellent review on this subject was published by Beaman and Isasi (1970). In their investigation, they critically examined forty different computer programs with respect to accuracy, content, and versatility. Finally, recommendations were made for different types of applications.

This paper will deal with four repeated series of microprobe analyses. To perform the micro- probe data reduction during this work, three basically different types of programs were applied. Interest is mainly centered on a comparison of the final results as computed by the different methods. Not very much attention is devoted to the comparison of microprobe analyses with conventional wet chemical analyses. The programs used in this work are based on the procedures followed by 1) Brown (1965), 2) Springer (1967) and 3) Bence and Albee (1968) for calculating the corrected results in electron microprobe analysis. Certain details regarding these programs are referred to later on in this paper.

\section{Experimental}

The material analysed in this study was collected among garnets and silicate glasses, which are currently used as microprobe standards in 
Table 1.

Wet chemical analyses of materials examined. The mean of analyses I/2 and II/2 was used as the standard for the microprobe analyses.

\begin{tabular}{|c|c|c|c|c|c|c|c|c|}
\hline & \multicolumn{2}{|c|}{ No. 1} & \multicolumn{2}{|c|}{ No. 2} & \multirow[t]{2}{*}{ No. 4} & \multirow[t]{2}{*}{ No. 7} & \multirow[t]{2}{*}{ No. 8} & \multirow[t]{2}{*}{ No. 9} \\
\hline & I & I & I & II & & & & \\
\hline $\mathrm{SiO}_{2} \ldots \ldots$ & 36.48 & 36.58 & 37.17 & 37.82 & 37.33 & 41.75 & 40.57 & 38.23 \\
\hline $\mathrm{TiO}_{2} \ldots$ & 0.50 & 0.50 & 0.09 & 0.06 & & 0.03 & 0.04 & 0.18 \\
\hline $\mathrm{Al}_{2} \mathrm{O}_{3} \ldots$ & 6.80 & 7.13 & 19.96 & 20.22 & 21.14 & 23.64 & 22.96 & 20.88 \\
\hline $\mathrm{FeO}$ tot.. & 23.12 & 23.03 & 36.95 & 36.06 & 29.88 & 10.01 & 15.80 & 25.86 \\
\hline $\mathrm{MnO} \ldots$ & 0.56 & 0.56 & 1.43 & 1.33 & & 0.44 & 0.41 & 0.57 \\
\hline $\mathrm{MgO} \ldots$. & 0.00 & 0.00 & 2.40 & 2.39 & 8.36 & 19.67 & 15.19 & 4.67 \\
\hline $\mathrm{CaO} \ldots$. & 30.22 & 30.00 & 1.76 & 1.78 & & 4.51 & 4.29 & 9.21 \\
\hline Total & 97.68 & 97.80 & 99.76 & 99.66 & 96.71 & $\overline{100.05}$ & 99.26 & 99.60 \\
\hline $\mathrm{Fe}_{2} \mathrm{O}_{3} \ldots$ & 21.94 & 21.84 & 4.33 & & 33.12 & 0.98 & 1.92 & 1.26 \\
\hline $\mathrm{FeO} \ldots \ldots$ & 3.33 & 3.33 & 33.05 & & & 9.13 & 14.07 & 24.73 \\
\hline $\mathrm{Cr}_{2} \mathrm{O}_{3} \ldots$ & & & 0.02 & & & 0.41 & 0.41 & 0.02 \\
\hline $\mathrm{Na}_{2} \mathrm{O} \quad \ldots$ & 0.03 & 0.03 & 0.06 & 0.03 & & 0.04 & 0.04 & 0.22 \\
\hline $\mathrm{K}_{2} \mathrm{O} \quad \ldots$ & 0.02 & 0.02 & 0.04 & 0.03 & & & 0.01 & 0.02 \\
\hline $\mathrm{P}_{2} \mathrm{O}_{5} \ldots$ & & & 0.16 & 0.06 & & 0.04 & 0.03 & 0.08 \\
\hline $\begin{array}{l}\mathrm{CO}_{2} \ldots \ldots \\
\mathrm{H}_{2} \mathrm{O}+\cdots\end{array}$ & 0.06 & 0.06 & $\begin{array}{l}0.00 \\
0.02\end{array}$ & & & & & \\
\hline $\mathrm{H}_{2} \mathrm{O}^{-} \ldots$ & & & 0.02 & & & & & \\
\hline $\mathrm{Cu} \ldots \ldots$ & 0. & $00^{+}$ & & & & & & \\
\hline Sr $\ldots \ldots$ & 0. & $00^{+}$ & & & & & & \\
\hline $\mathrm{Y}_{2} \mathrm{O}_{3} \ldots$ & & $00^{+}$ & & & & & & \\
\hline $\mathrm{ZrO}_{3} \ldots$ & 0. & $01^{+}$ & & & & & & \\
\hline $\mathrm{BaO} \ldots$. & & $00^{+}$ & & & & & & \\
\hline
\end{tabular}

No. 1. LH/Virtasalmi-66. Analyst Marie Smejkalova/ Väinö Hoffren XRF+.

No. 2. ML/Sulkava. 32/KK/65. Analyst Pentti Ojanperä. Anal. Nos. Rb 23/68 (I) and Rb 22/70 (II).

No. 4. Silicate glass No. 31/Hans Annersten. Uppsala, Sweden.

our laboratory. To ascertain the reliability of the conventional wet chemical analyses, two duplicate analyses were performed (specimen No. 1 and standard garnet No. 2). The wet chemical analyses of the garnets and the silicate glass examined during this work are presented in Table 1. In this table, the seven main components and their totals are given. Also the trace elements detected in the wet analyses and the XRF-analyses are reported. The footnote indicates the origin of these materials.

The specimens to be examined were fixed in one large polished section with every mineral grain ground, polished and coated equally. Thus the difficulties in preparing a number of mechanically similar samples were avoided. The electrical conductivity was achieved by coating the pol-
No. 7. 2507/Brian Goulson, Canberra University, Australia.

No. 8. 2539/Brian Goulson, Canberra University, Australia.

No. 9. 2544/Brian Goulson, Canberra University, Australia.

ished section with copper in vacuo. The whole series of analyses was performed by the author by using the Geoscan electron probe analyser at the Geological Survey of Finland. The analytical conditions were as follows: Acceleration voltage was set up at $20 \mathrm{kV}$ for each analysed element. Specimen current for the mineral grain used as the standard was $78.5 \mathrm{nA}$, as recorded on the specimen current meter of the microprobe. The currents for the analysed grains varied between 78.4 and $80.4 \mathrm{nA}$. However, the specimen current for every individual grain was exactly constant during the whole fourfold series. High vacuum was used throughout the probe system. The Mylar window situated between the column and the spectrometer space was kept open. The flow counters with $97 \% \mathrm{~A}+3 \% \mathrm{CO}_{2}$ gas mixture 
TABle 2.

Analytical conditions

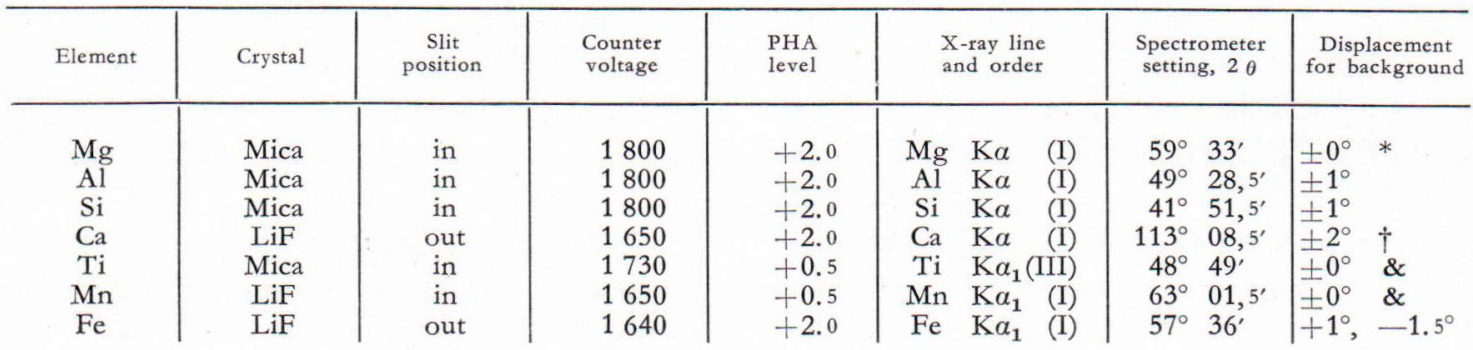

* Background measured on sample No. 1

+ Background measured on $\pm 2^{\circ}$ because of existence of the calcium $\mathrm{K}$-satellite lines

$\&$ Background measured on sample No. 4

were used for recording the $\mathrm{X}$-ray intensities. In Table 2, the specific analytical settings for each element are given with respect to crystal, slit position, counter voltage, PHA level, analysed line and its order, spectrometer position and the displacement of the spectrometer for the background measurements. The $2 \theta$ position of the maximum intensity of the analytical X-ray line was sought up for each element independently on the former spectrometer settings. Thus a valuable control of the spectrometer facilities, especially of the good angular repeatability, was obtained. The intensities were recorded by using the scaler mode of analysing. The time intervals varied from 10 to 40 seconds for a single measurement. In the calculation of the results, the sum of three single recordings was accepted to present an X-ray line intensity of an element. During the first series, the $\mathrm{X}$-ray line intensities of $\mathrm{Na}, \mathrm{K}$ and $\mathrm{P}$ were also tested. However, the concentrations of these elements proved to be below the detection limit in each specimen. In the last three series, these elements were not considered any more.

Before computers were used in the data processing, the measured intensities were corrected for drift, dead time and background. The calculations were performed by using an electronic desk-top calculator. These corrections changed the detected intensities only slightly. The actual data processing consisted of the calculations needed for the absorption, atomic number, characteristic fluorescence and continuous fluorescence (Bremsstrahlung) corrections. The total correction factors, the corrected concentrations and the sums of the analysed elements, and the number of the iterations needed during computions were given in the output lists. The data reduction with different computers was performed independently without the results from the other processings being known.

\section{Computer programs}

Three different kinds of computer programs were used in calculating the final results. Programs 1 and 2 differ mainly in the way the observed standard intensity is handled. On the third procedure, the experimental correction factors are used. In the following, some details of these data processing methods are discussed.

$\mathrm{Program}$ 1. The program is based on the paper published by Brown (1965). The original program was slightly modified and written in PL/I language by Mr. V. Suokonautio at the computer centre of the Outokumpu Co. in Helsinki. Also the data processing was carried out at the same centre with an IBM 360/40 computer. In this program, the measured intensity of a 
standard element is at first converted into the theoretical intensity from a "pure element» standard. The obtained intensity is then used as a reference intensity during the calculation process. Philibert's procedure is used with Heinrich's mass-absorption coefficients when the absorption correction is performed. The fluorescence corrections are made according to Castaing's procedure. No separate atomic number correction is applied in this program.

The effect of different values of the $\mathrm{h}$ - and sigma-factors on the absorption correction was examined during the data processing. The following pairs were used:

$$
\begin{aligned}
& \mathrm{h}=1.2 \frac{\sum \mathrm{c}_{\mathrm{i}} \mathrm{A}_{\mathrm{i}}}{\sum\left(\mathrm{c}_{\mathrm{i}} \mathrm{Z}_{\mathrm{i}}\right)^{2}} \text { with } \sigma_{20} \mathrm{kV}=3725, \\
& \mathrm{~h}==\quad \sum \mathrm{c}_{\mathrm{i}} \mathrm{h}_{\mathrm{i}} \quad \text { with } \sigma_{20} \mathrm{kV}=3725 \text { and } \\
& \mathrm{h}=\quad \sum \mathrm{c}_{\mathrm{i}} \mathrm{h}_{\mathrm{i}} \quad \text { with } \sigma=\frac{4.5 \cdot 10^{5}}{\mathrm{E}_{\mathrm{o}}^{1.65}-\mathrm{E}_{\mathrm{c}}^{1.65}}
\end{aligned}
$$

In these equations the symbols have the following meanings:

c concentration of an element

A atomic weight of an element

$\mathrm{Z}$ atomic number of an element

$\mathrm{E}_{\mathrm{o}}$ beam voltage in $\mathrm{kV}$

$\mathrm{E}_{\mathrm{c}}$ critical excitation potential in $\mathrm{kV}$.

The best fit with the conventional wet analyses was obtained by applying the last pair of factors. Then these values were used throughout the computing.

Program 2. The program is based on the paper by Springer (1967). This method directly uses the measured intensities from the standard sample for the calculations of the final, corrected results. The program is written in ALGOL language because a GE-600 computer was used at the Nokia Electronics Co. in Helsinki. The absorption correction is applied by means of Philibert's procedure. The mass-absorption coefficients are calculated in the manner proposed by Kelly (1966). The method published by Frazer
(1967) offers an alternative. A combination of the Kelly and Frazer calculation procedures can also be applied. This leads to only very slight differences in the final results. In this program, the sigma-values given by $\left(2.39 \cdot 10^{5}\right) /\left(\mathrm{E}_{\mathrm{o}}^{1.5}-\mathrm{E}_{\mathrm{c}}^{1.5}\right)$ are used. The h-factor is calculated to be equal to $\sum \mathrm{c}_{\mathrm{i}} \mathrm{h}_{\mathrm{i}}$. The subroutines for atomic number effect and for continuous fluorescence follow those given by Springer (op. cit.). The correction for the characteristic fluorescence is computed in a subroutine incorporating the procedure published by Reed (1965).

Program 3. The program follows the method published by Bence and Albee (1968). For handling the rough microprobe data, they proposed a calculation procedure in which only experimental $\alpha$-factors are used. The factors are specific for different types of microprobes, depending on the incident beam angle with the specimen surface and on the take-off angle of the measured $\mathrm{X}$-rays. Therefore these $\alpha$-factors must be calculated separately for each type of machine. The use of the $\alpha$-factors is quite simple and easy because the analyst is not bothered with the complicated physics and mathematics of the actual events during the whole microprobe analysis. The required data processing time is also extremely short. The $\alpha$-factors for the Geoscan electron probe analyser were kindly supplied for the author by Professor Arden L. Albee at the California Institute of Technology, Pasadena, California. Program 3 used in this work is written in BASIC language. The computing was carried out by the HP 2100 computer recently installed at the Geological Survey of Finland, Otaniemi.

\section{Results}

In Table 3, some of the detailed results of four independent series are presented. Each of these three metal oxides have been computed by using different kinds of programs. The corresponding results obtained by using the other programs (e.g., $\mathrm{MgO}$ with prog. 1 and prog. 3, etc.) are 
TABLE 3 .

Single microprobe determinations of $\mathrm{MgO}, \mathrm{Al}_{2} \mathrm{O}_{3}$ and $\mathrm{FeO}$ in the four series of analyses. The mean values of the four series for each analysed element are presented in Table 4.

\begin{tabular}{l|l|l|l|l|l}
\hline & No. 1 & No. 4 & No. 7 & No. 8 & No.9 \\
\hline \multirow{2}{*}{$\mathrm{MgO} \ldots . .}$. & 0.0 & 8.73 & 19.68 & 15.53 & 5.68 \\
& 0.0 & 9.44 & 19.46 & 15.23 & 5.62 \\
& 0.0 & 8.45 & 18.79 & 15.20 & 5.59 \\
& 0.0 & 8.91 & 19.31 & 15.42 & 5.60 \\
$\mathrm{Al}_{2} \mathrm{O}_{3} \ldots$ & & & & & \\
& 6.70 & 20.34 & 22.44 & 21.66 & 20.74 \\
& 6.47 & 21.30 & 22.70 & 22.63 & 21.58 \\
& 6.48 & 20.65 & 22.69 & 22.59 & 21.55 \\
& 6.92 & 21.48 & 23.11 & 21.98 & 21.40 \\
$\mathrm{FeO} \ldots . .$. & 21.82 & 29.86 & 9.15 & 15.77 & 24.91 \\
& 21.76 & 29.76 & 9.29 & 15.86 & 25.04 \\
& 22.03 & 29.97 & 9.26 & 16.00 & 25.13 \\
& 22.26 & 30.33 & 9.30 & 16.02 & 25.31
\end{tabular}

$\mathrm{MgO}$ Computed by using the modified Springer program (program 2).

$\mathrm{Al}_{2} \mathrm{O}_{3}$ Computed by using the Bence and Albee method (program 3).

$\mathrm{FeO}$ Computed by using the modified Brown program (program 1).

almost idential. There are only small deviations between the single results of the different methods, as is suggested by the mean values of each series (given in Table 4). The good repeatability of the electron microprobe analysis is supported by the series shown in Table 3. One might also obtain an idea of the expected homogeneity of the materials examined.

The final computed results are presented in Table 4 . With respect to each element, there are four rows, the meaning of which is given in the footnote of the table. The wet chemical analysis of sample No. 1 is the mean of two separate analysis (Table 1). The microprobe analyses presented in Table 4 are the means of four single determinations, some examples of which were given in the foregoing. $\mathrm{SiO}_{2}$ analyses show a slight positive bias, up to 2.7 per cent excluding Sample No. 4. It is evident that this positive deviation might at least partly be derived from the standard. If analysis I/No. 2 from Table 1 is taken as the reference value, a better fit between the $\mathrm{SiO}_{2}$ analyses (wet vs. micro-
TABLE 4.

Chemical analyses and final, computed results of microprobe analyses

\begin{tabular}{|c|c|c|c|c|c|}
\hline & No. 1 & No. 4 & No. 7 & No. 8 & No. 9 \\
\hline \multirow[t]{4}{*}{$\mathrm{SiO}_{2}$} & 36.53 & 37.33 & 41.75 & 40.57 & 38.23 \\
\hline & 37.07 & 39.77 & 42.69 & 41.65 & 39.28 \\
\hline & 36.45 & 39.90 & 42.13 & 41.43 & 39.21 \\
\hline & 36.83 & 39.73 & 42.40 & 41.45 & 39.15 \\
\hline \multirow[t]{4}{*}{$\mathrm{TiO}_{2}$} & 0.50 & & 0.03 & 0.04 & 0.18 \\
\hline & 0.51 & 0.00 & 0.03 & 0.04 & 0.13 \\
\hline & 0.50 & 0.00 & 0.03 & 0.04 & 0.14 \\
\hline & 0.55 & 0.00 & 0.03 & 0.04 & 0.14 \\
\hline \multirow[t]{4}{*}{$\mathrm{Al}_{2} \mathrm{O}_{3}$} & 6.96 & 21.14 & 23.64 & 22.96 & 20.88 \\
\hline & 6.64 & 20.94 & 22.73 & 22.21 & 21.32 \\
\hline & 6.59 & 20.96 & 22.19 & 21.93 & 21.19 \\
\hline & 6.55 & 20.92 & 22.61 & 22.11 & 21.23 \\
\hline \multirow[t]{4}{*}{$\mathrm{FeO}$. } & 23.07 & 29.88 & 10.01 & 15.80 & 25.86 \\
\hline & 22.23 & 30.06 & 9.35 & 16.05 & 25.26 \\
\hline & 22.40 & 29.98 & 9.24 & 15.93 & 25.22 \\
\hline & 21.97 & 29.98 & 9.25 & 15.91 & 25.10 \\
\hline \multirow[t]{4}{*}{$\mathrm{MnO}$} & 0.56 & & 0.44 & 0.41 & 0.57 \\
\hline & 0.46 & 0.00 & 0.36 & 0.33 & 0.51 \\
\hline & 0.47 & 0.00 & 0.36 & 0.33 & 0.51 \\
\hline & 0.45 & 0.00 & 0.35 & 0.33 & 0.50 \\
\hline \multirow[t]{4}{*}{$\mathrm{MgO}$} & 0.00 & 8.36 & 19.67 & 15.19 & 4.67 \\
\hline & 0.00 & 8.94 & 20.25 & 15.82 & 5.71 \\
\hline & 0.00 & 8.88 & 19.31 & 15.34 & 5.62 \\
\hline & 0.00 & 8.92 & 20.14 & 15.73 & 5.66 \\
\hline \multirow[t]{4}{*}{$\mathrm{CaO}$} & 30.11 & & 4.51 & 4.29 & 9.21 \\
\hline & 31.71 & 0.02 & 4.32 & 4.40 & 8.85 \\
\hline & 31.76 & 0.02 & 4.35 & 4.43 & 8.89 \\
\hline & 31.36 & 0.02 & 4.27 & 4.37 & 8.81 \\
\hline \multirow[t]{4}{*}{ Total } & 97.74 & 96.71 & 100.05 & 99.26 & 99.60 \\
\hline & 98.62 & 99.73 & 99.73 & 100.50 & 101.06 \\
\hline & 98.17 & 99.74 & 97.61 & 99.43 & 100.78 \\
\hline & 97.71 & 99.57 & 99.05 & 99.94 & 100.59 \\
\hline
\end{tabular}

Analyses presented in order:

- wet chemical analysis,

- microprobe analysis, data processing by using the Bence and Albee method (program 3),

- microprobe analysis, data processing by using the modified Springer program (program 2),

- microprobe analysis, data processing by using the modified Brown program (program 1).

probe) will result. The exceptionally large deviation in one $\mathrm{SiO}_{2}$ analysis (No. 4) may be caused by the synthetic origin of this material. The greatest difference between the synthetic and most of the natural materials is oxidation state of the iron. Further, there may exist hetero- 
geneous spots on this sample, as is indicated (?) by the individual analyses in Table 3 .

As to the minor elements in these specimens, $\mathrm{TiO}_{2}$ and $\mathrm{MnO}$, the microprobe analyses tend to result in smaller concentrations than the conventional analyses. This is quite a normal result because the higher concentrations in wet analyses may be caused by the impurities found in natural minerals. However, these differences are negligible in normal mineralogical studies.

For aluminum, the microprobe analyses are below the values given by the wet analyses except in one case (sample No. 9). Difficulties in complete separation of $\mathrm{R}_{2} \mathrm{O}_{3}$ group oxides from each other during wet chemical processes may lead to analyses in which the values of $\mathrm{Al}_{2} \mathrm{O}_{3}$ are too high, as was reported by Knowles et al. (1968, p. 448).

The slight negative bias in the microprobe analyses for $\mathrm{FeO}$ may be corrected in this case by choosing the reference analysis properly, just as in the case of $\mathrm{SiO}_{2}$. The use of analysis I/No. 2 as the $\mathrm{FeO}$ standard would slightly increase the values for microprobe analyses.

The agreement between the $\mathrm{MgO}$ and $\mathrm{CaO}$ analyses is fairly good throughout with the exceptions of $\mathrm{MgO}$ in sample No. 9 and $\mathrm{CaO}$ in sample No. 1. Both of these show an appreciable positive bias with respect to the conventional analyses.

Finally, the totals of the microprobe analyses do not differ greatly from the reference values given by the wet analyses. Specimen No. 4 shows the largest deviation, which is clearly due to the differences in the $\mathrm{SiO}_{2}$ analyses.

In conclusion, a comparison of the results given by different computing procedures shows that these figures differ from each other much less than they do from those yielded by the wet analyses. In processing electron microprobe data, any of these programs will give reasonable good results.

The main interest in this work has been in comparing various types of computer programs, which differ from each other greatly in their working principle. The values given in Tables 3 and 4 show that the choice among these three possibilities is merely personal. Each of these programs gives results that agree fairly well with the wet analyses. The agreement is so close that the computer programs may be used in mineralogical applications with no doubt about the final results. The computer programs work so well that the deviations caused by different types of computing procedures are negligible. In any attempt to improve the accuracy of the microprobe analysis, attention must be paid to the working methods and to the possible errors made by the analyst during the operation.

Acknowledgements - The author is indebted to $\mathrm{Mr}$. V. Suokonautio at the computer centre of the Outokumpu Co. and to Mr. E. Härkönen at Nokia Electronics for assistance in the data processing.

\section{REFERENCES}

BeAman, D. R. and Isasi, J. A. (1970) A critical examination of computer programs used in quantitative electron microprobe analysis. Anal. Chemistry 42, $1540-1568$.

Bence, A. E. and Albee, A. L. (1968) Empirical correction factors for the electron microanalysis of silicates and oxides. J. Geol. 76, 382-403.

Brown, J. D. (1965) A computer program for electron probe microanalysis. U. S. Department of the Interior Bureau of Mines Report No. 6648.

FRAZER, JANE Z. (1967) A computer fit to mass absorption coefficient data. Scripps Instutions of Oceanography Reference 67-29.
Kelly, T. K. (1966) Mass absorption coefficients and their relevance in electron-probe microanalysis. Trans. Instn. Min. Metall. B 75, 59-73.

Knowles, C. R., Smith, J. V., Bence, A. E. and Albee, A. L. (1969) X-ray emission microanalysis of rockforming minerals. VII. Garnets. J. Geol. 77, 439-451.

ReED, S. J. B. (1965) Characteristic fluorescence corrections in electronprobe microanalysis. Brit. J. Appl. Phys. 16, 913-926.

SPRINGER, G. (1967) Die Berechnung von Korrekturen für die quantitative Elektronenstrahl-Mikroanalyse. Fortschr. Miner. 45, $103-124$.

Manuscript received, May 26, 1972. 